nerve roots intrathecally, using $5 \%$ phenol in glycerin. In cases of causalgia and intermittent claudication the appropriate sympathetic nerves were blocked with absolute alcohol or $6 \%$ phenol in water after a diagnostic injection of $1 \%$ lignocaine had demonstrated that pain was effectively controlled.

The complications of this method of treatment were relatively few. Some patients complained of discomfort due to cutaneous anaesthesia, and a few developed transient paresis owing to involvement of motor nerves or roots, but disturbance of bladder control with temporary incontinence of urine was seen in only five patients. Though in 55 patients the results of treatment could not be assessed, $75 \%$ of the remainder had substantial relief of pain, and only in 19 patients in the entire series was the procedure unsuccessful. Thus this method of treatment can often help to diminish suffering in patients with intractable pain, though successful treatment does not diminish the need for sympathetic understanding of the patient and his problems. Nevertheless, as the doctor's experience of the technique increases he usually finds that he has also improved his ability to deal satisfactorily with the psychological aspects of pain.

\section{Prophylaxis of Choriocarcinoma}

The antifolic-acid drug methotrexate is of value in the treatment of choriocarcinoma. ${ }^{12}$ Its success was at first attributed to the need of the foetus for relatively large amounts of folic acid. ${ }^{3}$ Only later was it appreciated that the beneficial cytotoxic effect of the drug is achieved despite pronounced concomitant immunosuppression. The discovery that actinomycin $D$ is also very effective in the treatment of choriocarcinoma ${ }^{5}$ served to make the mechanism by which beneficial effects are produced less clear. In the case of Burkitt's lymphoma there is some evidence ${ }^{6}$ that the best results from treatment with methotrexate are obtained with doses high enough to exert an antifolic-acid effect but insufficient for really deep depression of the patient's capacity to react immunologically. Less than maximal treatment of choriocarcinoma with methotrexate, however, probably leads to drug resistance rather than to better results. ${ }^{7}$ More hopeful are regimens that include the administration of folinic acid, so that the dosage of methotrexate can be pushed up into what would otherwise be the lethal range. ${ }^{8}$ The use of methotrexate or actinomycin $D$ has improved survival from choriocarcinoma from less than $30 \%$ by hysterectomy alone to between 50 and $80 \%$, the actual figures depending on the criteria for initial diagnosis and the particular therapeutic regimen. ${ }^{9}$

Success with methotrexate in the treatment of choriocarcinoma led naturally to the question, Could progression from hydatidiform mole to choriocarcinoma be prevented by administration of the drug ? $^{10}$ A report by C. P. Manahan and his colleagues ${ }^{11}$ indicated that a single intensive course of treatment with $75 \mathrm{mg}$. methotrexate did not abolish the risk of progression from mole to fatal choriocarcinoma. $\mathbf{K}$. Koga and K. Maeda ${ }^{12}{ }^{13}$ have recently reported more favourably on the prophylactic use of methotrexate. Of 107 patients treated with methotrexate after removal of hydatidiform mole none developed choriocarcinoma, and in only two was there subsequent evidence of invasion by residual mole tissue. By contrast 3 out of 42 patients treated by surgery alone developed choriocarcinoma and one developed invasive mole. Treatment by surgery followed by other chemotherapeutic agents, including thiotepa, cyclophosphamide, or mitomycin $\mathrm{C}$, gave similar results to that by surgery alone. In most cases the dose of methotrexate given was $10 \mathrm{mg}$. a day for seven days. But for three patients administration was more prolonged because of persistent gonadotrophin excretion. It could be argued that in these cases the effect of the drug may have been therapeutic rather than prophylactic. Evaluation of the results of Koga and Maeda is complicated by the fact that an unspecified number of the patients in the group which received miscellaneous anticancer agents also received methotrexate in combination. Moreover, it seems that the clinical trial was uncontrolled in the sense that patients were not allocated to the different treatment groups by random selection. Eighty-four of the 107 patients in the methotrexate-tested group showed signs of drug toxicity.

In Great Britain the risk of progression from mole to choriocarcinoma in the absence of treatment is close to $2.5 \%$, which is much less than the $7.1 \%$ encountered by Koga and Maeda in Japan. The extent to which this difference is real, or depends on differences in diagnostic criteria, is uncertain. But, however it is explained, even if their findings with regard to the prophylactic value of methotrexate are confirmed, it would be difficult in Britain to justify the exposure of 40 women to the toxic effects of the drug in expectation that one would benefit. Indeed, except in units with special experience of cytotoxic drug therapy, the risk of death from methotrexate toxicity might well exceed that from choriocarcinoma.

The development of an improved method for the assay of urinary gonadotrophins ${ }^{14} 15$ may, if it can be made more generally available, enable the selection of a group of patients who have had hydatidiform mole and remain at special risk. This group might include merely the 15 to $20 \%$ who are still excreting chorionic gonadotrophins more than three months after removal of a mole. Of these, perhaps only those in whom sequential estimations do not show a falling titre should seriously be considered as candidates for methotrexate prophylaxis.

' Li, M. C., Hertz, R., and Spencer, D. B., Proc. Soc. Exp. Biol. (N.Y.), 1956, 93, 361.

${ }^{2}$ Hertz, R., Bergenstal, D. M., Lipsett, M. B., Price, E. B., and Hilbish, T. F., f. Amer. med. Ass., 1958, 168, 845 .

s Nelson, M. M., and Evans, H. M., F. Nutr., 1949, 38, 11.

- Bagshawe, K. D., in Modern Trends in Gynaecology, Series 3, ed. R. J. Kellar, p. 38.1963. London.

b Ross, G. T., Stolbach, L. L., and Hertz, R., Cancer Res., 1962, 22, 1015.

- Brit. med. F., 1966, 1, 1043.

Hertz, R., in U.I.C.C. Monograph No. 3, “Choriocarcinoma," p. 66, ed. J. F. Holland and M. M. Hreshchyshyn. 1967. Berlin.

- Bagshawe, K. D., and Wilde, C. E., f. Obstet. Gynaec. Brit. Cwlth, 1964, 71, 565 .

' See U.I.C.C. Monograph No. 3, “ Choriocarcinoma," ed. J. F. Holland and M. M. Hreschyshyn. 1967. Berlin.

to Manahan, C. P., Benitez, I., and Estrella, F., Amer. F. Obstet. Gynec., $1961,82,641$.

" Manahan, C. P., Abad, R., and Lopez, A. M., in U.I.C.C. Monograph No. 3, "Choriocarcinoma," p. 72, ed. J. F. Holland and M. M. Hreschyshyn. 1967. Berlin.

12 Koga, K., and Maeda, K., in U.I.C.C. Monograph No. 3, "Choriocarcinoma," p. 76, ed. J. F. Holland and M. M. Hreshchyshyn. 1967. Berlin.

13 Koga, K., and Maeda, K., Amer. F. Obstet. Gynec., 1968, 100, 270.

1. Wilde, C. E., and Bagshawe, K. D., Ciba Foundation Study Group No. 22, p. 46, ed. G. E. W. Wolstenholme and J. Knight. 1965. London.

is Bagsbawe, K. D., Wilde, C. E., and Orr, A. H., Lancet, 1966, 1, 1118. 